\title{
Mathematical Modeling of Ammonium Persulfate Granules Dissolution in Sulfuric Acid
}

\author{
E.N. Tugolukov*, E.V. Galunin, A.V. Tarov, \\ N.R. Memetov, A.G. Tkachev \\ Department of Technologies and Equipment for Nanoproduction, Tambov State Technical University, \\ 1, Leningradskaya St., Tambov, 392000, Russian Federation \\ * Corresponding author: Tel.: + 7 (910) 85331 56.E-mail: tugolukov.en@mail.ru
}

\begin{abstract}
The technology of obtaining graphene-based materials via graphite intercalation involves dissolution of solid ammonium persulfate granules in sulfuric acid. The objective of mathematical modeling of the process of synthesizing such materials is to develop a methodology for calculating parameters of industrial equipment. In this regard, an interval algorithm for simulating processes with moving interface boundaries is used herein. Mathematical models were presented for the dissolution of solid ammonium persulfate granules in sulfuric acid during and without mixing. The conditions of the mass transfer from the granule surface were considered in both cases. The developed mathematical models make it possible to assess the dissolution kinetics and the time for complete granules dissolution depending on the conditions of the process and the conditions ensuring its completion within a specified time frame.
\end{abstract}

\section{Keywords}

Graphite intercalation compound; graphene; finite integral transforms; process simulation.

\section{Nomenclature}

$\tau$ - current time, $\mathrm{s} ; d \tau$ - time interval, $\mathrm{s} ; D(\tau)$ - diameter of the spherical granule, $\mathrm{m} ; \beta$ - mass transfer coefficient, $\mathrm{m} / \mathrm{s}$; $F(\tau)$ - actual surface area of the granule, $\mathrm{m}^{2} ; \rho_{\mathrm{s}}$ - density of the granule material, $\mathrm{kg} / \mathrm{m}^{3} ; c^{*}-$ temperature-dependent equilibrium concentration of the granule substance in solution, $\mathrm{kg} / \mathrm{m}^{3} ; c-$ actual concentration of the granule substance in solution, $\mathrm{kg} / \mathrm{m}^{3} ; N u_{d}=\beta D / D_{S}-$ Nusselt diffusion number; $\mathrm{Re}=w D \rho / \mu-$ Reynolds number; $S c=v / D_{S}-\mathrm{Schmidt}$ number; $D_{s}$ - diffusion coefficient for ammonium persulfate dissolution in sulfuric acid, $\mathrm{m}^{2} / \mathrm{s} ; w$ : peripheral velocity of a mixing device activator, $\mathrm{m} / \mathrm{s} ; \rho-$ density of sulfuric acid, $\mathrm{kg} / \mathrm{m}^{3} ; \mu-$ dynamic viscosity of sulfuric acid, Pa.s; $v-\mathrm{kinematic}$ viscosity of sulfuric acid, $\mathrm{m}^{2} / \mathrm{s} ; a(r, \tau)$ : concentration pattern of ammonium persulfate in sulfuric acid, $\mathrm{kg} / \mathrm{m}^{3} ; f(r)$ - initial distribution of ammonium persulfate in sulfuric acid, $\mathrm{kg} / \mathrm{m}^{3} ; R_{0}$ - actual radius of the ammonium persulfate particle, m; $R_{1}-$ radius of a spherical region where the ammonium persulfate particle is dissolved, $\mathrm{m} ; r$ - radial coordinate, $\mathrm{m} ; \mu_{n}, \varphi_{n}-$ characteristic numbers.

(C) E.N. Tugolukov, E.V. Galunin, A.V. Tarov, N.R. Memetov, A.G. Tkachev, 2016

\section{Introduction}

Graphene has been increasingly used in various fields owing to its unique physicochemical and thermal properties [1-3]. Developing an efficient, cheap and scalable process is actually the most important problem in its high-yield industrial fabrication.

Graphene-based materials are usually produced as multi- or few-layered graphene nanoplatelets (GNPs) which are composed of thin stacks of platelet-shaped graphene sheets. Exfoliation of graphite materials (especially, surfactant-assisted ultrasonic exfoliation of well-ordered crystalline graphite in water, organic solvents or supercritical liquids) is one of the most promising routes for mass production of such materials $[4,5]$. Among techniques put forward to improve the graphite exfoliation into GNPs, graphite intercalation seems a simpler and more effective way $[6,7]$. 
Considering the aforementioned, the technological procedure of the exfoliation of a cold-expanded graphite intercalation compound in the presence of ammonium persulfate and sulfuric acid has been designed at the Department of Technology and Methods of Nanoproducts Manufacturing of Tambov State Technical University and "NanoTechCenter" Ltd. (both - Tambov, Russia).

In this regard, to ensure the organization of new industrial production, the development of a design of industrial equipment for fabricating graphene-based materials could be the next phase of complex research and development activities, where it is highly required to make mathematical models that would predict almost all important process characteristics.

Thus, at the current stage, the aim of the present study is to develop a methodology for calculating parameters of the industrial equipment regarding the dissolution of ammonium persulfate granules in sulfuric acid.

\section{Materials and Methods}

A more complete understanding of laws governing the dissolution process and its features can be achieved via mathematical field modeling of target parameters such as temperature, concentration, pressure, strength, velocity, etc. The quality of calculation techniques involved ensures their adequacy to simulated processes, reliability of implementation and validity of results obtained is of fundamental importance. Analytical approaches to the mathematical modeling of target parameter fields for industrial equipment meet these requirements.

A clear method of digitizing spatial and temporal coordinates, together with an assumption underlying the constancy of process parameters in the spatiotemporal region, allows avoiding the use of non-linear problem statements in mathematical physics that generally do not assume analytical solutions and significantly complicate numerical solutions.

The method consists in representing the fields of determining parameters as a set of fields of spatiotemporal regions that can be simulated by using analytical solutions to systems of linear partial differential equations solved under corresponding single-valuedness conditions.

\section{Results}

The process of synthesizing multi-layered graphene materials via graphite intercalation (Fig. 1) involves the following steps:

- dissolution of ammonium persulfate granules in sulfuric acid;

- processing of crystalline graphite using the ammonium persulfate solution in sulfuric acid;

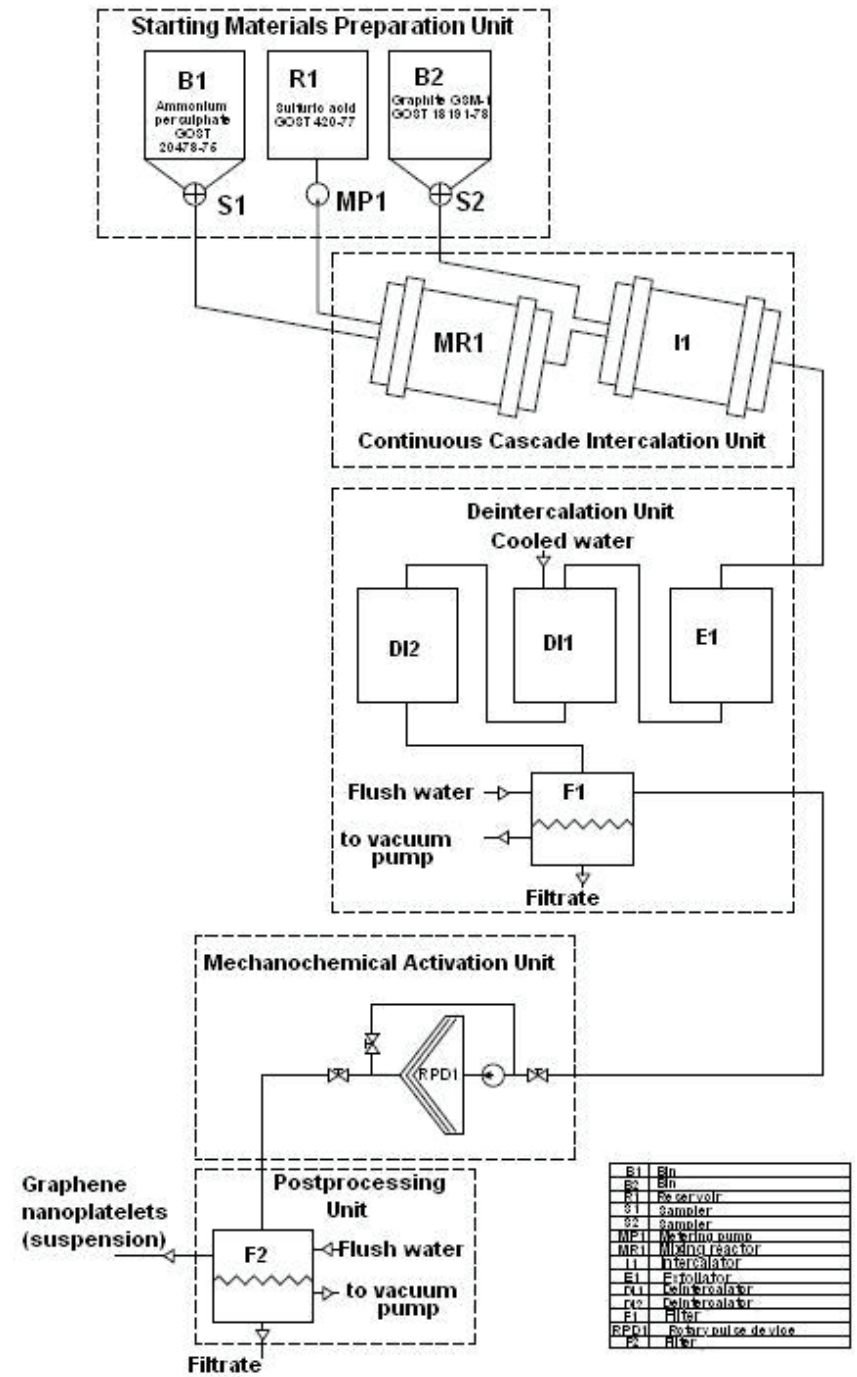

Fig. 1. Flow sheet for obtaining GNPs

- ageing of the obtained graphite intercalation compound before its expansion;

- hydrolysis;

- washing of the expanded graphite intercalation compound (EGIC) to remove the sulfuric acid;

- dispersion of the EGIC using an ultrasonic cavitation device;

- partial dehydration of the product.

The method for calculating parameters of industrial equipment to manufacture graphene-based materials includes mathematical models of the main production processes.

The solution is prepared by dissolving ammonium persulfate granules in sulfuric acid. The mathematical model of this process allows evaluating the dissolution kinetics and the time for complete dissolution of the granules under the process conditions which include mixing, temperature and initial granule size. The model also makes it possible to determine the conditions that ensure completion of the process within a specified time frame. 


\subsection{Dissolution of Ammonium Persulfate Granules during Mixing}

It is assumed herein that the dissolution of the ammonium persulfate granules is due to the mass transfer from the granule surface into the liquid phase during the mixing.

At the current time $\tau$, the diameter of a spherical granule equals $D(\tau)$. The amount of substance transferred from the granule surface into the liquid phase during a time interval $d \tau$ while mixing can be calculated as follows:

$$
d M=\beta F(\tau)\left(c^{*}-c\right) d \tau .
$$

The same amount of substance can be expressed in terms of changes in the granule diameter:

$$
\begin{gathered}
d M=\frac{4}{3} \pi\left(D^{3}(\tau)-D^{3}(\tau+d \tau)\right) \rho_{s} . \\
F(\tau)=\pi D^{2}(\tau) .
\end{gathered}
$$

By comparing Eqs. (1) and (2), and considering Eq. (3), we get:

$$
\frac{4}{3} \pi\left(D^{3}(\tau)-D^{3}(\tau+d \tau)\right) \rho_{s}=\beta \pi D^{2}(\tau)\left(c^{*}-c\right) d \tau,
$$

after the transforms including the passage to the limit at $\mathrm{d} \tau \rightarrow 0$, this expression can be written as follows:

$$
\frac{d D(\tau)}{d \tau}+\frac{\beta\left(c^{*}-c\right)}{4 \rho_{s}}=0 .
$$

With the initial condition presented by Eq. (6):

$$
D(0)=D_{0}
$$

the solution to Eq. (5) will be as follows:

$$
D(\tau)=D_{0}-\frac{\beta\left(c^{*}-c\right)}{4 \rho_{s}} \tau \text {. }
$$

The mass transfer coefficient for the particle dissolution in a wide range of Reynolds numbers can be determined according to Eq. (8):

$$
N u_{d}=0.16 \operatorname{Re}^{0.62} S c^{0.5} .
$$

Since the mass transfer coefficient is a function of the particle diameter, and the concentration of the granule substance in the solution depends on the time, the parameters of the granule dissolution are calculated at successive short time intervals, during each of which the mass-transfer coefficient and the concentration of the solution are considered constant.

\subsection{Dissolution of Ammonium Persulfate Granules without Mixing}

The field of ammonium persulfate concentrations in the acid surrounding the granule can be simulated through solving a non-stationary problem for diffusion in a hollow sphere according to the following equations:

$$
\begin{gathered}
\frac{\partial a(r, \tau)}{\partial \tau}=D_{s}\left(\frac{\partial^{2} a(r, \tau)}{\partial r^{2}}+\frac{2}{r} \frac{\partial a(r, \tau)}{\partial r}\right) ; \\
R_{0} \leq r \leq R_{1} ; \\
a(r, 0)=f(r) ; \\
a\left(R_{0}, \tau\right)=\rho_{s} ; \\
\frac{\partial a\left(R_{1}, \tau\right)}{\partial r}=0 .
\end{gathered}
$$

The solution to this problem is obtained by an integral transform technique along the coordinate $r$, relative to the boundary concentration $\rho_{s}$. The use of finite integral transforms is described in [8].

The transition to images is performed according to the following formula:

$$
A(\tau)=\int_{R_{0}}^{R_{1}} r^{2} a(r, \tau) P(r) d r .
$$

Herein, $P(r)$ is the solution to the auxiliary problem:

$$
\begin{gathered}
\frac{d^{2} P(r)}{d r^{2}}+\frac{2}{r} \frac{d P(r)}{d r}+\frac{\mu^{2}}{D_{s}} P(r)=0 ; \\
P\left(R_{0}\right)=0 ; \\
\frac{d P\left(R_{1}\right)}{d r}=0 .
\end{gathered}
$$

This solution, up to a constant factor, is given by Eq. (17):

$$
P(r)=\frac{1}{r} \sin \left(\frac{\mu_{n}}{\sqrt{D_{s}}} r+\varphi_{n}\right) ;
$$

and the numbers $\mu_{n}$ and $\varphi_{n}$ determined based on Eqs. (15) and (16):

$$
\varphi_{n}=\pi n-\frac{\mu_{n}}{\sqrt{D_{s}}} R_{0}
$$

where the numbers $\mu_{n}$ are consecutive positive roots of the equation

$\frac{\mu_{n}}{\sqrt{D_{s}} R_{1}} \cos \left(\frac{\mu_{n}}{\sqrt{D_{s}}} R_{1}+\varphi_{n}\right)-\frac{1}{R_{1}^{2}} \sin \left(\frac{\mu_{n}}{\sqrt{D_{s}}} R_{1}+\varphi_{n}\right)=0$. 
By considering Eq. (13), the integral images of the problem described by Eqs. (9)-(12) are as follows:

$$
\begin{gathered}
\frac{d A(\tau)}{d \tau}=-\mu^{2} A(\tau) ; \\
A(0)=\int_{R_{0}}^{R_{1}} r^{2}(f(r)-\rho) P(r) d r .
\end{gathered}
$$

The solution to this problem is given below:

$$
A(\tau)=A(0) \exp \left(-\mu^{2} \tau\right) .
$$

According to the reverse transition formula, it can be transformed as follows:

$$
a(r, \tau)=\rho_{s}+\sum_{n=1}^{\infty} \frac{A(\tau)}{N} P(r) ;
$$

(the summation is taken over the values of $\mu_{n}$ ) where

$$
\begin{aligned}
N & =\int_{R_{0}}^{R_{1}} r^{2} P^{2}(r) d r= \\
& =\frac{R_{1}}{2}-\frac{\sqrt{D_{s}}}{2 \mu} \sin \left(\frac{\mu}{\sqrt{D_{s}}} R_{1}+\varphi\right) \cos \left(\frac{\mu}{\sqrt{D_{s}}} R_{1}+\varphi\right)- \\
& -\frac{R_{0}}{2}+\frac{\sqrt{D_{s}}}{2 \mu} \sin \left(\frac{\mu}{\sqrt{D_{s}}} R_{0}+\varphi\right) \cos \left(\frac{\mu}{\sqrt{D_{s}}} R_{0}+\varphi\right) .
\end{aligned}
$$

At the current time $\tau$, the diameter of the spherical granule equals $D(\tau)$. The amount of the substance transferred from the granule surface into the liquid phase during a time interval $d \tau$ without mixing can be estimated as follows:

$$
d M=-D_{s} \frac{\partial a\left(R_{0}, \tau\right)}{\partial r} F(\tau) d \tau .
$$

By comparing Eqs. (24) and (2), and considering Eq. (3), we get:

$\frac{4}{3} \pi\left(D^{3}(\tau)-D^{3}(\tau+d \tau)\right) \rho_{s}=-D_{s} \frac{\partial a\left(R_{0}, \tau\right)}{\partial r} \pi D^{2}(\tau) d \tau$,

after the transforms including the passage to the limit at $\mathrm{d} \tau \rightarrow 0$, the equation can be modified as follows:

$$
\frac{d D(\tau)}{d \tau}-\frac{D_{s}}{4 \rho_{s}} \frac{\partial a\left(R_{0}, \tau\right)}{\partial r}=0 .
$$

With the initial condition described by Eq. (6), the solution to this equation will be as follows:

$$
D(\tau)=D_{0}+\frac{D_{s}}{4 \rho_{s}} \frac{\partial a\left(R_{0}, \tau\right)}{\partial r} \tau .
$$

In this case, the parameters of the granule dissolution are also calculated at successive short time intervals, during each of which the concentration gradient near the granule surface of granules is considered constant.

\section{Discussion}

The approach to mathematical modeling of nonstationary processes proposed herein has been tested in our previous studies [9-11]. It has some characteristic features and imposes a number of specific requirements on the formulation of linear problems, thereby allowing for reducing the solution to a non-linear problem to a set of solutions for corresponding linear problems. Thus, in general, initial conditions must be random, and design profiles obtained for the end of the previous time domain of the current unit area may in special cases be used as initial distribution.

The finite integral transform method possesses some practical advantages over the other analytical techniques:

- it is unified for solving problems with various formulations and does not require ingenuity in technical methods;

- it allows for finding solutions to problems with inhomogeneous boundary conditions without representing the problem as a set of stationary and non-stationary components;

- it assumes simultaneous transforms in several (or all) spatial coordinates, as well as in coordinates, along which the changes in medium properties are stepwise;

- it allows for finding solutions in the standard form suitable for computer implementation.

The main difference between finite-limit integral transforms and operational calculus lies in using a wide range of transforms, the kernels and weight functions of which are determined individually for each specific problem.

\section{Conclusions}

1. The methodology for calculating parameters of equipment for the industrial production of graphenebased materials via graphite intercalation was developed based on mathematical modeling of consecutive processing steps.

2. The modeling approaches used were illustrated by an example of modeling the process of dissolving solid ammonium persulfate granules in sulfuric acid during and without mixing. The interval algorithm for simulating processes with moving interface boundaries was employed.

3 . The simulation results obtained were used in developing the technological scheme for obtaining GNPs (Fig. 1) at "NanoTechCenter" Ltd. (Tambov, Russia). 


\section{Acknowledgment}

The present research was carried out within the framework of the Federal Target Program "Research and Development in Priority Areas of the Scientific and Technological Complex of Russia for 2014-2020" (State Contract of July 22, 2014: No 14.577.21.0091, Unique Identifier for Applied Scientific Research: RFMEFI57714X0091).

\section{References}

1. Soldano, C., Mahmood, A. and Dujardin, E. (2010) Production, properties and potential of graphene. Carbon, (48), 2127-2150.

2. Potts, J.R. et al (2011) Graphene-based polymer nanocomposites. Polymer, (52), 5-25.

3. Li, A., Liu, J. and Feng, S. (2014) Applications of graphene-based materials in energy and environmental science. Science of Advanced Materials, (6), 209-234.

4. Hernandez, Y. et al. (2008) High-yield production of graphene by liquid-phase exfoliation of graphite. Nature Nanotechnology, (3), 563-568.

5. Lotya, M. et al. (2009) Liquid phase production of graphene by exfoliation of graphite in surfactant/water solutions. Journal of the American Chemical Society, (131), 3611-3620.

6. Inagaki, M. et al. (2014) Advanced Materials Science and Engineering of Carbon. Amsterdam, Elsevier Publ.
7. Melezhyk, A.V. \& Tkachev, A.G. (2014) Synthesis of graphene nanoplatelets from peroxosulfate graphite intercalation compounds. Nanosystems: Physics, Chemistry, Mathematics, 5 (2), 294-306.

8. Tugolukov, E.N. (2004) Matematicheskoe modelirovanie tehnologicheskogo oborudovaniya mnogoassortimentnykh kmimicheskikh proizvodstv. [Mathematical Modeling of Manufacturing Equipment for the Multi-Purpose Chemical Industry]. Moscow, Mashinostroenie Publ. (Rus)

9. Tugolukov, E.N. and Egorov, E.S. (2014) Metodika matematicheskogo modelirovaniya termodinamicheskih protsessov porshnevogo kompressora [Methods for mathematical modeling of thermodynamic processes occurring in the reciprocating compressor]. Vestnik Astrahanskogo gosudarstvennogo tehnicheskogo universisteta, (1), 45-53. (Rus)

10. Akulinin, E.I. et al. (2012) Modelirovanie protsessa obogascheniya vozduha kislorodom $v$ ustanovke korotkotsiklovoy adsorbtsii [Modeling the oxygen air enrichment process on a pressure swing adsorption facility]. Khimicheskaya tehnologiya, (13), 247-256. (Rus)

11. Tkachev, A.G. and Tugolukov, E.N. (2008) Matematicheskoe modelirovanie temperaturnyh polei opytno-promyshlennogo reaktora sinteza uglerodnyh nanomaterialov [Mathematical modeling of the temperature field in an experimental-industrial reactor for synthesis of carbon nanomaterials]. Vestnik Izhevskogo gosudarstvennogo tehnicheskogo universisteta, 1 (37), 24-26. (Rus) 